\title{
The Wellness Center in Public Hospitals in Thailand: A Qualitative Assessment Using RE-AIM Model
}

\author{
Utoomporn WONGSIN ${ }^{\mathrm{a}, 1}$, Arnat WANNASRI ${ }^{\mathrm{b}, \mathrm{c}}$, Kwanpracha \\ CHIANGCHAISAKULTHAI ${ }^{\mathrm{d}}$ and Tuo-Yu CHEN ${ }^{\mathrm{a}, \mathrm{e}}$ \\ a PhD Program in Global Health and Health Security, College of Public Health, Taipei \\ Medical University, Taiwan \\ ${ }^{b}$ Nopparat Rajathanee Hospital, Department of Medical Services, Ministry of Public \\ Health, Thailand \\ ${ }^{c}$ National Yang Ming Chiao Tung University, Taiwan \\ dinternational Health Policy Program (IHPP), Thailand \\ ${ }^{e}$ Master Program in Global Health and Development, College of Public Health, Taipei \\ Medical University, Taiwan
}

\begin{abstract}
Non-communicable diseases (NCDs) become one of serious health issues globally including Thailand. The Wellness Center was introduced by the Ministry of Public Health (MOPH) in public hospitals since 2018 for both healthy people and people who at risk for NCDs. It incorporates risk evaluation, health assessment, health behaviors changing, health promotion and prevention, and health record system to follow participant's health status. This study aimed to evaluate the Wellness Centers in three public hospitals in Thailand using RE-AIM framework. Findings indicated that the Wellness Centers successful reached its target groups. Although sample size was small, the findings provided a positive outcome. Besides, the average weight and Body Mass Index (BMI) had reduced significantly after participants attending both services of Wellness Centers. However, there were some challenges from this program such as financial sustainability, performance indicator, and data system.
\end{abstract}

Keywords. Wellness Center, Qualitative assessment, NCDs, Prevention and promotion program, RE-AIM model

\section{Introduction}

Non-communicable diseases (NCDs) are serious health issues in global level. In Thailand, of $75 \%$ of all death in 2009 attributed to NCDs. Stroke, diabetes and ischemic heart disease were top three of NCDs [1]. The economics loss from NCDs was also high in Thailand. It was estimated that the costs of NCDs were approximately USD 6,158 million in 2013 [2]. In 2011, the Thai cabinet introduced the Thailand Healthy Lifestyle Strategic Plan for 2011-2020 [3] to encourage the ministries to collaborate in controlling NCDs. The Ministry of Public Health (MOPH) - as a main organization of this plan -

${ }^{1}$ Corresponding Author, Utoomporn Wongsin, PhD Program in Global Health Department, College of Public Health, Taipei Medical University, Taiwan; Email: d537108007@tmu.edu.tw. 
introduced NCDs and health risks with focuses on promotion and prevention program to improve health issues. Four main diseases included in this plan are cardiovascular disease, diabetes, chronic obstructive pulmonary disease, and cancer. Risk factors included in this plan are smoking, drinking, unhealthy diet, and lack of physical exercise. Several kinds of promotion and prevention programs were introduced and implemented in public hospitals by MOHP such as the NCDs Clinic Plus 2017. The Wellness Center was also introduced by the MOPH in public hospitals in 2018 for both healthy people and people who at risk of NCDs. A pilot of Wellness Centers implemented in 16 public hospitals in the same year. The Wellness Center incorporates risk evaluation, health assessment, health behaviors modifications, health promotion and prevention, and health record system to follow participant's health status. However, only Wellness Centers from three public hospitals had available data for us to do the evaluation. This study used REAIM model to evaluate Wellness Center program of the three public hospitals.

\section{Methods}

We used the Reach, Effectiveness, Adoption, Implementation and Maintenance (REAIM) framework to evaluate program. This study conducted in three public hospitals in Thailand selected by purposive sampling. Data were retrospectively collected from hospitals' database in fiscal year 2019. Inclusion criteria were hospitals have prevention and promotion services, and an adequate data to evaluate the program. The Wellness center had two services including services and fitness service. There were three service process in this program, including assessment, empowerment, and coaching. Each participant received services once a month for six months. Besides, individual fitness services were planned by a sport science.

\section{Results}

Two hundred and thirty-five participants from three public hospitals in 2019 were analyzed. Their ages were from 14 to 67 years old, with an average age of 43 years old. Most participants were female (69.1\%). Participants were general people (NCDs patients and walk-in). Over 50\% of the participants had Body Mass Index (BMI) at least 25. And 57 participants had Hypertension, Diabetes and Dyslipidemia. A total of 132 participants attended NCD programs for more than two months

Overall, the results showed that weight and BMI of participants changed significantly. Considering in each hospital, participants from hospital B had the highest weight changed (5.77) after attending a program followed by hospital C (3.97) and A (1.89), respectively. For BMI, participants from hospital B had the highest BMI changed (2.4) after attending a program followed by hospital C (1.63). However, there was not BMI changed from participants from hospital A.

Table 1. The Wellness Centers evaluation using RE-AIM model

\begin{tabular}{|c|c|c|}
\hline RE-AIM Framework & Wellness Center & Notes \\
\hline Reach (Individual) & $\begin{array}{l}\text { There were } 4 \text { target groups. } \\
\text { 1. People at risk of NCDs who } \\
\text { has annual health checks from } \\
\text { hospital. }\end{array}$ & $\begin{array}{l}\text { 1.Target groups covered healthy } \\
\text { people and people who are at risk } \\
\text { of NCDs following The Wellness } \\
\text { Center policy. }\end{array}$ \\
\hline
\end{tabular}




\begin{tabular}{|c|c|c|}
\hline & $\begin{array}{l}\text { 2.People who willing to attend } \\
\text { program. } \\
\text { 3.Patients from NCDs clinics } \\
\text { 4. Hospital staff. }\end{array}$ & $\begin{array}{l}\text { 2.However, sample sizes were } \\
\text { low and they were not good } \\
\text { representative sample but the } \\
\text { result showed a positive outcome. }\end{array}$ \\
\hline Efficacy (Individual) & $\begin{array}{l}\text { An average of weight and Body } \\
\text { Mass Index (BMI) had reduced } \\
\text { significantly after participants } \\
\text { attending Wellness center } \\
\text { program. }\end{array}$ & $\begin{array}{l}\text { Motivation process plays a crucial } \\
\text { role in behavior changing. }\end{array}$ \\
\hline Adoption (Setting level) & $\begin{array}{l}\text { 1.A pilot study in } 16 \text { public } \\
\text { hospitals during year } 2018 \text { but } \\
\text { there were only } 3 \text { public } \\
\text { hospitals had enough data to } \\
\text { evaluate the program. } \\
\text { 2.A total } 253 \text { participants from } \\
3 \text { public hospitals attended the } \\
\text { program (using data 2019) }\end{array}$ & $\begin{array}{l}\text { One Wellness Center provided } \\
\text { services to hospitals employees } \\
\text { only. }\end{array}$ \\
\hline $\begin{array}{c}\text { Implementation (setting/staff } \\
\text { level) }\end{array}$ & $\begin{array}{l}\text { Only } 132 \text { from } 253 \text { participants } \\
\text { attended programs for more than } \\
\text { two months. }(52 \%)\end{array}$ & $\begin{array}{l}48 \% \text { of total participants attended } \\
\text { program less than two months. } \\
2 . \text { They were unwillingness to } \\
\text { attend the program. }\end{array}$ \\
\hline $\begin{array}{c}\text { Maintenance } \\
\text { (Individual and Setting level) }\end{array}$ & $\begin{array}{l}\text { 1. This program still continues } \\
\text { providing services in hospitals } \\
\text { and expanding to other public } \\
\text { hospitals. } \\
\text { 2. It is included in P\&P package } \\
\text { which has annually budget from } \\
\text { three main insurance schemes in } \\
\text { Thailand. } \\
\text { 3. It is collaboration between } \\
\text { Department of Disease Control, } \\
\text { Department of NCDs and } \\
\text { Department of Health, MOPH. }\end{array}$ & $\begin{array}{l}\text { 1.Financial sustainability (many } \\
\text { projects include in } P \& P \text { package). } \\
\text { 2.Program (service and fitness). }\end{array}$ \\
\hline
\end{tabular}

\section{Discussion and Conclusion}

The results show that an average of weight and Body Mass Index (BMI) had reduced significantly after participants attending Wellness Center both service and fitness program. This is in line with previous studies indicated that lifestyle modification intervention, weight reduction can be reduced the incidence of people at high risk living with diabetes [5], [6] improving NCDs risk factors [7],[8], [9] and it also increase quality of life [10].

The Wellness Centers from Three public hospitals in Thailand successful reached its target groups needed both healthy people and people who at risk for noncommunicable diseases (NCDs) which contributes in strengthening public health.

However, there are some challenges from this program

1. Data system should be managed to provide adequate data, we found that some information was not completed. Hospital uses paper-based to record participant's information.

2. The Wellness Center program was based on hospital financing, and some hospitals collect a small money from participants. Therefore, long term financing should be prepared by hospital and governments to ensure financial sustainable. 
3. There was a difference in services process between three hospitals which may impact to the results. Diet Coaching, for example, one hospital taught participants by conducting workshops and food model. Also, they gave advice to participants via line application. Whereas, two hospital provide knowledge by using food model. Thus, a standard guideline should be preparing to ensure that program is more effective.

4. There was not an evaluation process/ a standard performance indicators for the wellness center program which are necessary improving program. To ensure that this program is much more effective to target groups, a set of indicators and evaluation process should be regulated.

Further studies are recommended to involve more Wellness centers providing services at hospitals to improve generalizability of our findings.

\section{Acknowledgments}

The authors would like to acknowledge hospital directors and staff from three public hospitals, National Health Foundation, International Health Program, Thailand, and College of Public health, Taipei Medical University, Taiwan.

\section{References}

[1] International health program, Thailand. Burden of Disease and injury of the Thai population in Thailand 2014 [Internet]. [cited 2018 September 25]. Available from: http://bodthai.net/en/download/burden-ofdiseases-and-injuries-of-thai-population-in-2014-english-report-151118-np_final/

[2] NCDs - Thaihealth. Thai Health Promotion Foundation. [Internet]. [cited 2018 September 25]. Available from: https://www.thaihealth.or.th/microsite/categories/5/ncds/2/173/176-+NCDs.html. (In Thai)

[3] Ministry of public health. Thailand healthy lifestyle strategic plan B.E 2011-2020 [Internet]. [cited 2018 September 25]. Available from: http://wops.moph.go.th/ops/oic/data/20110316100703_1_.pdf(In Thai)

[4] Glasgow RE, Harden SM, Gaglio B, Rabin B, Smith ML, Porter GC, et al. RE-AIM Planning and Evaluation Framework: Adapting to New Science and Practice with a 20-Year Review. Front Public Health. 2019 Mar 29; 7:64.

[5] Knowler WC, Barrett-Connor E, Fowler SE, Hamman RF, Lachin JM, Walker EA, et al. Reduction in the incidence of type 2 diabetes with lifestyle intervention or metformin. N Engl J Med. 2002 Feb 7;346(6):393-403.

[6] Hamman RF, Wing RR, Edelstein SL, Lachin JM, Bray GA, Delahanty L, et al. Effect of weight loss with lifestyle intervention on risk of diabetes. Diabetes Care. 2006 Sep;29(9):2102-7.

[7] Wing RR, Lang W, Wadden TA, Safford M, Knowler WC, Bertoni AG, et al. Benefits of modest weight loss in improving cardiovascular risk factors in overweight and obese individuals with type 2 diabetes. Diabetes Care. 2011 Jul;34(7):1481-6.

[8] Salas-Salvadó J, Díaz-López A, Ruiz-Canela M, Basora J, Fitó M, Corella D, et al. Effect of a Lifestyle Intervention Program with Energy-Restricted Mediterranean Diet and Exercise on Weight Loss and Cardiovascular Risk Factors: One-Year Results of the PREDIMED-Plus Trial. Diabetes Care. 2019 May 1;42(5):777-88.

[9] Gregg EW, Lin J, Bardenheier B, Chen H, Rejeski WJ, Zhuo X, et al. Impact of Intensive Lifestyle Intervention on Disability-Free Life Expectancy: The Look AHEAD Study. Diabetes Care. 2018 May;41(5):1040-8..

[10] Langan A, Bader A, Goedkoop S, Cummings S, Tsikitas M, Nogueira I, et al. A longitudinal study to investigate the effects of a 12-week comprehensive lifestyle weight management program on body weight and quality of life. Clin Nutr ESPEN. 2020 Dec; 40:125-32. 